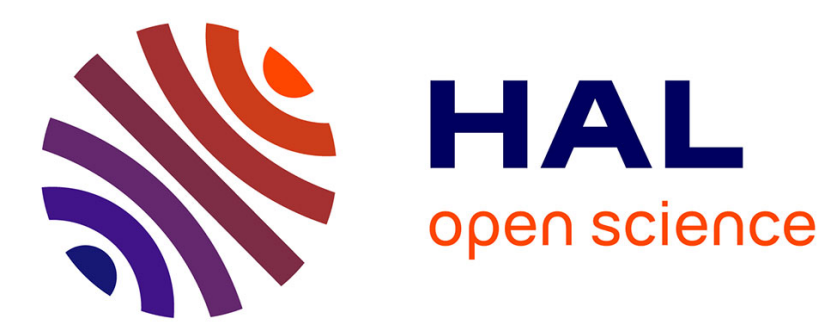

\title{
Extraction of tungsten as polyoxometalate anion using a layered double hydroxide: Selectivity and regeneration
}

Grégory Lefèvre, Julie Lion, Aurélie Makolana

\section{To cite this version:}

Grégory Lefèvre, Julie Lion, Aurélie Makolana. Extraction of tungsten as polyoxometalate anion using a layered double hydroxide: Selectivity and regeneration. Separation Science and Technology, 2018, 54 (4), pp.549-558. 10.1080/01496395.2018.1505911 . hal-02380871

\section{HAL Id: hal-02380871 \\ https://hal.science/hal-02380871}

Submitted on 26 Nov 2019

HAL is a multi-disciplinary open access archive for the deposit and dissemination of scientific research documents, whether they are published or not. The documents may come from teaching and research institutions in France or abroad, or from public or private research centers.
L'archive ouverte pluridisciplinaire HAL, est destinée au dépôt et à la diffusion de documents scientifiques de niveau recherche, publiés ou non, émanant des établissements d'enseignement et de recherche français ou étrangers, des laboratoires publics ou privés. 
Extraction of tungsten as polyoxometalate anion using a layered double hydroxide: selectivity and regeneration

Grégory Lefèvre*, Julie Lion, Aurélie Makolana

PSL Research University, Chimie ParisTech - CNRS, Institut de Recherche de Chimie Paris, 75005, Paris, France

* corresponding author : gregory.lefevre@chimie-paristech.fr 
Abstract

Extraction of tungstate species as highly-charged polyoxometalates has been performed using a carbonated double layer hydroxide, hydrotalcite. An optimal $\mathrm{pH}$ around 5 has been determined. Two extraction mechanisms have been shown using in situ infrared spectroscopy and zeta potential measurement: exchange of carbonate ions by heptatungstate species and adsorption by innersphere surface complexes formation. The presence of foreign anions (nitrate, chloride, sulfate) has no effect on the extraction efficiency. Regeneration of the solid was carried out with a solution of carbonate sodium at $\mathrm{pH} 10$, and the subsequent extraction step has shown no loss of efficiency. 


\section{Introduction}

Tungsten and its alloys and compounds are important materials in several industrial applications.

Thus, tungsten carbides are well known in the domain of material for their outstanding properties of high level of hardness and wear resistance ${ }^{1}$. It is also used in other domains as electronics (anticathodes, interruptors, lasers, mobile phone vibrating components, ...) 2,3 $^{2,3}$ or generator of radioisotope $\mathrm{Re}-188^{4}$. The main source of tungsten is its ores, the most important minerals are wolframite (iron manganese tungstate) and scheelite (calcium tungstate) ${ }^{2}$. However, recycling is another possible source. The treatment of tungsten alloys scraps is the major part of this source ${ }^{5}$ but spent hydro-desulphurization catalysts contain also an important amount of tungsten which can be recovered ${ }^{6}$. Moreover, wastewater from printed circuit board recycling unit is another opportunity to recover tungsten ${ }^{7}$.

Several recovering and separation methods of tungsten from its aqueous solutions have been studied. In the processing of the ores, a tungsten solution can be obtained after alkali leaching or fusion ${ }^{8}$. The extraction of the element as $\mathrm{W}(\mathrm{VI})$ species has been performed using solvent extraction by various types of amines ${ }^{8}$. The optimal extraction $\mathrm{pH}$ is between 1 and 5 and $\mathrm{W}_{10} \mathrm{O}_{32}{ }^{4-}$, expected to be the main species at $\mathrm{pH} 1$, is assumed to be extracted by the ammonium group. Stripping was then performed using $\mathrm{NH}_{3(\text { as) }} 4$ mol. $\mathrm{L}^{-18}$. Other processes based on ion exchange in resins have been studied ${ }^{9,10}$. Adsorption on ferric hydroxide ${ }^{6}$ has been also tested, and precipitation with divalent cations ${ }^{11}$. The extraction of tungsten from aqueous solution remains a process to improve, by decreasing the cost or the environmental impact, or by extending the range of sources that can be treated. Even though the affinity of tungstate polyanions towards layered double hydroxides (LDH) is known ${ }^{12}$, to the best of our knowledge no study on the application of these solids has been performed to evaluate the use of LDH to extract tungsten from a solution, and to describe the extraction mechanism. LDHs are inorganic materials that consist of positively charged stacked layers with charge-balancing anions located in the interlayer regions. They can be represented by the general formula $\left[\mathrm{M}^{2+}{ }_{1-\mathrm{x}} \mathrm{M}^{\prime 3+}{ }_{\mathrm{x}}(\mathrm{OH})_{2}\right]^{\mathrm{q+}} \mathrm{A}^{\mathrm{n}-}{ }_{\mathrm{q} / \mathrm{n}} \cdot \mathrm{mH}_{2} \mathrm{O}$ where $\mathrm{M}^{2+}$ and $\mathrm{M}^{\prime 3+}$ represent metal cations of 
valence $z$ and 3 respectively, with $z$ being generally equal to 1 or $2, x$ corresponds to the molar ratio of $\mathrm{M}^{\prime 3+} /\left(\mathrm{M}^{2+}+\mathrm{M}^{\prime 3+}\right)$, $\mathrm{q}$ is the net charge carried by a layer, $\mathrm{A}^{\mathrm{n}-}$ stands for the interlayer anion of valence $n$, and $m$ is a positive number. Most generally, $z$ is equal to $2, q$ is thus equal to $x$, and the structure of a given layer is similar to a brucite sheet $\left(\mathrm{Mg}(\mathrm{OH})_{2}\right)$ made of octahedral units in each of which a metal cation is coordinated by hydroxyl groups. It is worth noting that the interlayer bonding is governed by Coulombic and $\mathrm{H}$-bonding interactions. So the stronger Coulombic attraction with the metal hydroxide layer is found when the intercalated anion has the higher charge ${ }^{13}$. Thus, polymer ions as polyoxometallates which are characterized by very high negative charge present a huge affinity towards $\mathrm{LDHs}^{14-16}$.

Due to the high anion-exchange capacities (2-3 meq/g), their relatively low cost, and their environmental-friendly composition, LDHs have been studied for numerous applications, as wastewater treatment to scavenge pollutant present as anionic species ${ }^{17-19}$. In this study, we present some results on the use of the most usual $\mathrm{LDH}$, hydrotalcite $\left(\mathrm{Mg}_{6} \mathrm{Al}_{2}\left(\mathrm{CO}_{3}\right)(\mathrm{OH})_{16}\right)$, to extract tungsten from aqueous solutions, and evaluated the selectivity of this process and the desextraction/regeneration step. In situ methods, as zetametry and Attenuated Total Reflectance infrared spectroscopy (ATR-IR), have been used to understand the sorption mechanism.

\section{Materials and methods}

\subsection{Chemicals}

The double layered hydroxide (hydrotalcite) sample comes from Sigma Aldrich (ref. 652288). Its formula is $\mathrm{Mg}_{6} \mathrm{Al}_{2}\left(\mathrm{CO}_{3}\right)(\mathrm{OH})_{16}, 4 \mathrm{H}_{2} \mathrm{O}$ (CAS 11097-59-9). The diffractogram is conform to the expected structure.

All solutions and suspensions in aqueous phase were prepared using purified water (Milli-Q, Millipore) with a resistivity of $18.2 \mathrm{M} \Omega . \mathrm{cm}$. An aqueous tungstate stock solution (0.1 M) was prepared from $\mathrm{Na}_{2} \mathrm{WO}_{4}, 2 \mathrm{H}_{2} \mathrm{O}$ (Acros Organic). 


\subsection{Adsorption experiments}

The sorption of tungsten has been performed following a batch protocol. About $50 \mathrm{mg}$ of hydrotalcite were suspended in $30 \mathrm{~mL}$ of water. The powder has been found very hydrophobic what prevents a good transfer of species from solution to the solid surface. Thus, a first hydration step was performed: the suspensions were sonicated in an ultrasound bath then stirred in a platform shaker overnight. The $\mathrm{pH}$ of each batch was then adjusted by several additions of $\mathrm{HCl} 1 \mathrm{M}$ or $\mathrm{NaOH} 1 \mathrm{M}$ (Fisher Scientific) or diluted solutions. After equilibration and a good homogenization of the suspension, $30 \mu \mathrm{L}$ of tungsten stock solution was added to obtain a total concentration of $10^{-4} \mathrm{M}$.

\subsection{Zetametry}

Malvern Nano ZS Zetasizer was used for the zeta potential measurements. $100 \mathrm{~mL}$ of a suspension of $1 \mathrm{~g} / \mathrm{L}$ of hydrotalcite has been prepared following the above protocol. After the hydration step, sodium hydroxide has been added to reach a pH value around 11. An electrolyte has been added to avoid the change of the ionic strength during the titration experiment. Sodium chloride $10^{-3} \mathrm{M}$ was used for measurement of hydrotalcite only, or hydrotalcite with $10^{-4} \mathrm{M}$ tungsten. Sodium chloride $10^{-}$

${ }^{2} \mathrm{M}$ was used for measurement of hydrotalcite with $10^{-3} \mathrm{M}$ tungsten. After a few minutes of equilibration, an aliquot was withdrawn and analyzed using the zetameter. It was then poured back in the reactor, and the $\mathrm{pH}$ has been decreased using $\mathrm{HCl}$ by a few fractions of $\mathrm{pH}$ unit. When the $\mathrm{pH}$ value was stable, a new aliquot was withdrawn, and the protocol was repeated until pH around 4.

\subsection{In situ ATR-IR spectroscopy}

The experimental conditions and setup are similar to those described in our previous articles ${ }^{12,20}$. The ATR-FTIR spectra were collected with a dry-air-purged Thermo Scientific Nicolet 6700 FT-IR equipped with a MCT detector. Spectral resolution was $4 \mathrm{~cm}^{-1}$ and spectra were averaged from 256 scans. The horizontal ZnSe crystal with a single reflection and an angle of incidence of $45^{\circ}$ (Smart PIKE) was coated with $1 \mu \mathrm{L}$ of the hydrotalcite suspension $(1 \mathrm{~g} / \mathrm{L})$ which was dried under a flow of $\mathrm{N}_{2}$. 
The flow cell was placed on the ATR element and a background was recorded in presence of the conditioning solution flowing at $1 \mathrm{~mL} / \mathrm{min}$ using a peristaltic pump (Ismatec S.A.) at room temperature. After stabilizing for at least $30 \mathrm{~min}$, a background spectrum was recorded and a given volume of a $0.1 \mathrm{M}$ sodium tungstate solution stock was subsequently added to the circulating solution. Anion exchange into the layered double hydroxides was followed by the acquisition of spectra in minute steps.

To decompose spectra, they have first been corrected of the ATR effect by Omnic software with the values of refractive indexes of water or air. Then, the decomposition by Gaussian or Voigt functions has been performed using Origin and Excel software.

\section{Results and discussion}

\subsection{Batch results}

A first series of batch experiments have been prepared to evaluate the effect of $\mathrm{pH}$, and the equilibrium state of the system. In Fig. 1A, results for experiments between 18 and 90h are shown. The first conclusion is that the equilibrium is almost reached after the smallest experiment time. The $\mathrm{pH}$ evolution during the experiment due to the strong buffer capacity of hydrotalcite has been corrected by small amounts of acid and base, what led to different values of $\mathrm{pH}$ for each time. A general observed trend is a decrease of the sorption with $\mathrm{pH}$ increase. This evolution can be separated in three parts: (1) for $\mathrm{pH}$ between 4.7 and 5.2, a plateau is reached and the fraction of sorbed tungsten is higher than $90 \%$; (2) a gradual decrease of the sorbed fraction as a function of $\mathrm{pH}$ is observed between $\mathrm{pH} 5.2$ and $\mathrm{pH} 8$; (3) no sorption of tungsten was measured for $\mathrm{pH}$ higher than 8. The knowledge of the speciation of tungsten in solution is useful to interpret this $\mathrm{pH}$ edge. Several sets of polymeric species and associated formation constants can be found in literature ${ }^{21}$. We have previously found ${ }^{12}$ that our experimental data are in agreement with the work by Cruywagen at al.

${ }^{22}$. However, the constants given in this article has been obtained in $1 \mathrm{M} \mathrm{NaCl}$ medium, and no 
thermodynamic constants calculated at infinite dilution were available. Thus in Fig. 1B, the speciation of $\mathrm{W}(\mathrm{VI})$ calculated in these conditions is shown, even though a slight difference with the real speciation, i.e. without $\mathrm{NaCl}$, can be expected. It can be concluded that the sorption is almost total when the speciation of tungsten is dominated by highly-charged heptamers. This observation is consistent with the exchange between carbonate ions initially present in the interlayer by tungsten heptamers previously observed with a Zn-AI LDH ${ }^{12}$. Indeed, the heptamers have a negative charge of 5- or 6-, what allows them to compete with carbonate ions initially present in the interlayer. Above $\mathrm{pH} 5.5$, the concentration in heptamers become negligible, but the sorption remains at a high level. In this domain, the exchange mechanism is not expected to occur, and another phenomenon could be responsible for this sorption. The formation of inner-sphere surface complexes can be assumed, with a possible surface polymerization as observed on some iron oxides ${ }^{23}$, or only through mono- or polydentate surface complexes. 


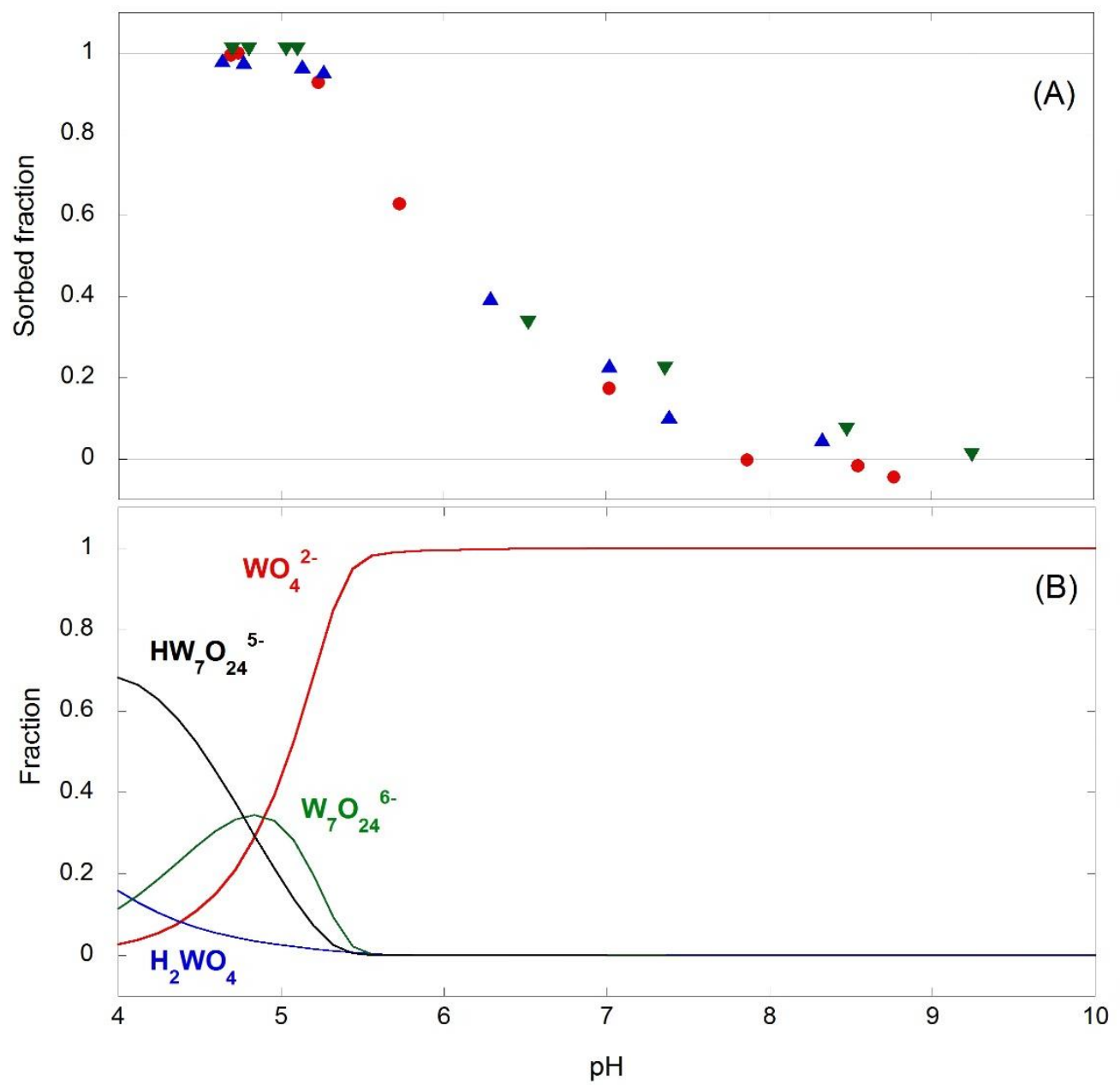

Fig 1. (A) Effect of pH on tungsten sorption on hydrotalcite with different equilibration times: $18 \mathrm{~h}$ $(\bullet), 30 h(\Delta)$, and $90 \mathrm{~h}(\boldsymbol{\nabla})$ and $(B)$ estimation of the speciation of $\mathrm{W}(\mathrm{VI})$ in solution for a total concentration of $10^{-4} \mathrm{M}$.

Even if the affinity of hydrotalcite towards tungsten was demonstrated, and so the possibility to use this solid to extract this element from water, it is important to evaluate a desextraction process, or even a regeneration protocol. This was done using a solution at high $\mathrm{pH}$, since in these conditions, tungsten is not sorbed (Fig. 1A). To favour the regeneration, carbonate ions have been added in the desextraction solution, leading to a final composition of $\mathrm{NaOH}(\mathrm{pH} 10)$ with $10^{-2} \mathrm{M}$ carbonate. After a 
first sorption step at different $\mathrm{pH}$ (Fig. 2), each batch was centrifugated, and the supernatant was replaced by the desextraction solution, and stirred during $120 \mathrm{~h}$, with an aliquot withdrawn after $30 \mathrm{~h}$. The final $\mathrm{pH}$ was around 10 in all samples. Two behaviours are observed. In the domain where the sorption was almost total, the desorption is only partial with a visible kinetic effect. Thus, for the lowest sorption $\mathrm{pH}$ values (4.43), around half of tungsten was desorbed after $30 \mathrm{~h}$, and this value reached ca. $70 \%$ after $120 \mathrm{~h}$. For higher $\mathrm{pH}(4.56,4.70)$, a larger part of the sorbed tungsten was desorbed, with a smaller kinetic effect. Another behavior is observed for $\mathrm{pH} 5.85-8.17$, where a total desorption was found as soon as $30 \mathrm{~h}$ (within the experimental uncertainties). Thus, the desorption phenomena are directly related to the observations made during the study of the sorption step. When an exchange mechanism is expected, the desorption is slower. The heptamers present in the interlayer could be desorbed following two mechanisms: either (1) the heptamers depolymerize inside the interlayer, and the carbonate ions replace them due to the decrease of the charge of tungsten species, or (2) the heptamers are directly replaced by carbonate ions, and this reaction is favoured by the absence of heptamers in solution, according Le Chatelier's law. In both cases, the reaction is expected to be slow, and some spectroscopic measurements (see below) are needed to choose between these two possibilities.

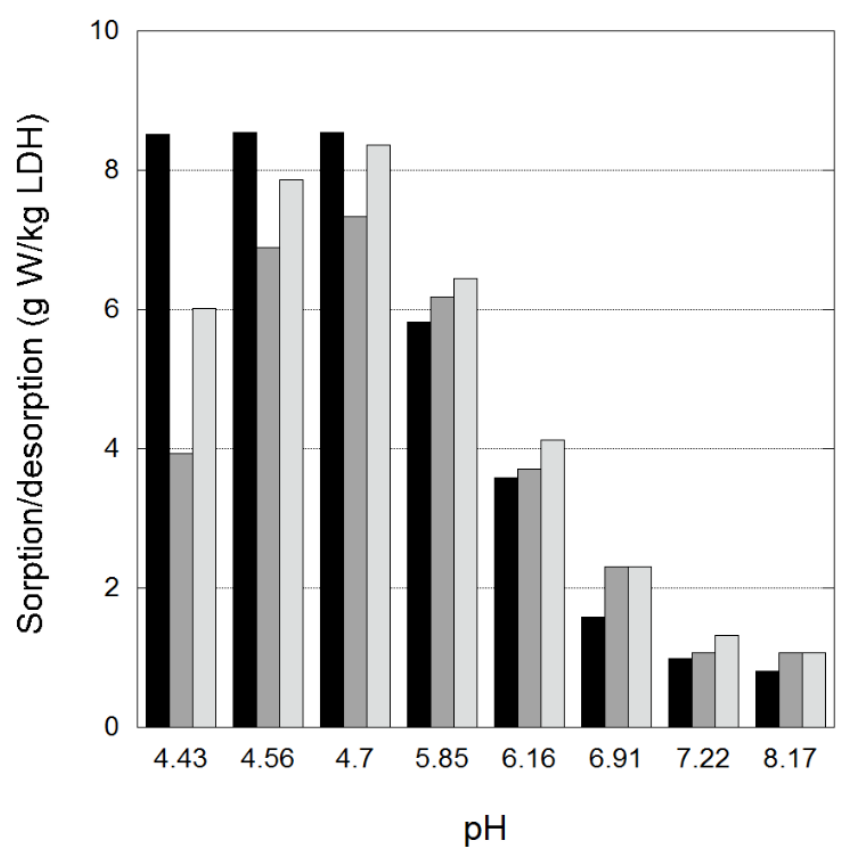


Fig. 2. Desorption efficiency as a function of sorption $\mathrm{pH}$ and time: sorbed amount at a given $\mathrm{pH}$ (black), desorption after 30h (dark grey) and 120h (light grey).

To evaluate the regeneration efficiency, another sorption step has been performed following the desorption described above. After centrifugation, the supernatant consisting in the desorption solution has been replaced by acidified tungsten solutions. The amount of tungsten sorbed on the regenerated hydrotalcite is shown in fig. $3 \mathrm{~A}$ and the comparison with the values obtained for the same LDH samples before the sorption/desorption step shows that the activity of the LDH has not been affected. 

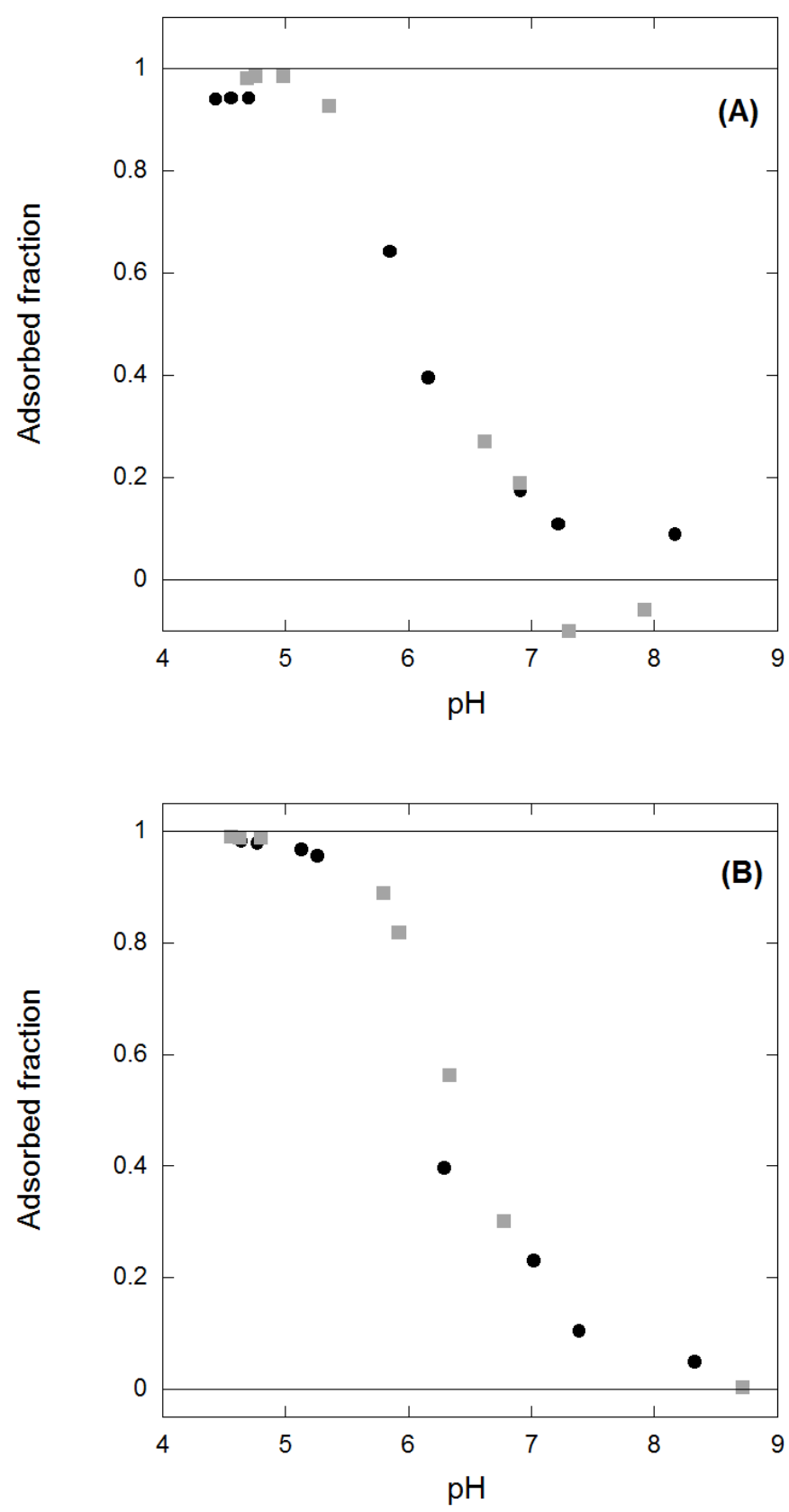

Fig. 3. Effect of $(A)$ regeneration: first sorption experiment $(\bullet)$ and second sorption experiment after regeneration $(\square)$, and (B) competitive anions on tungsten sorption: pure solution of tungsten $(\bullet)$ and solution of tungsten and other anions (see text for details) ( $\square$ ).

The initial choice of hydrotalcite to extract tungsten from solution was driven by an objective of selectivity, since the mineralization of this element would lead to a solution containing large amounts 
of other ions, coming from the chemicals used in the leaching step or from other elements dissolved together. This expected selectivity has been proven in a dedicated experiment where tungsten was present along with a mixture of chloride, nitrate, sulfate anions, each with a concentration one hundred times higher than those of tungsten. The result is shown in Fig. 3B, and it is noteworthy that no effect of these ions was observed. In the $\mathrm{pH}$ range where an exchange with heptamers occurs, this behavior was expected, since the affinity for these highly charged species is greater than those towards carbonate ions, known to have amongst the highest affinity towards anions (including those used in this experiment). Moreover, the absence of any effect of these anions on the sorption of tungsten at $\mathrm{pH}$ values higher than 5 is in agreement with a strong adsorption of tungstate as innersphere complexes. In the case of an outer-sphere complex, the presence of $\mathrm{Cl}^{-}, \mathrm{NO}_{3}{ }^{-}$and $\mathrm{SO}_{4}{ }^{2-}$ would have led to a decrease of the adsorbed fraction since they would have competed for the same reactive sites, these ions being known for their propensity to form electrostatic bonds with the surface of metallic oxides ${ }^{24}$.

\subsection{Zetametry}

To go further in the characterization of the sorbed tungsten, the zeta potential of particles has been measured as a function of $\mathrm{pH}$. This characterization method is very usual to study the reactivity of metal oxide particles since this is focused on the solid/solution interface. In the case of ion exchangers as LDHs, this can give results only on the reactions occurring at the external surfaces of particles, while mechanisms based on the exchange with interlayer anions cannot be probed. This is illustrated in a previous work on oxyanions sorption by LDHs ${ }^{17}$ : the same zeta potential evolution was found for an hydrotalcite calcined then exchanged with ions known to present a weak affinity for the surface (outer-sphere complexes), $\mathrm{Cl}^{-}$and $\mathrm{NO}_{3}{ }_{3}$, while the rehydration in solutions of phosphate or arsenate led to a decrease of the zeta potential, in agreement with an inner-sphere complexation on the LDH outer surfaces. The evolution of zeta potential of hydrotalcite as a function of $\mathrm{pH}$ is 
shown in Fig. 4: in the whole studied pH range, the surface remains positive. Then, the measurements have been performed in presence of increasing concentrations of tungstate. In presence of $1 \mathrm{mM}$, the values of zeta potential do not differ at $\mathrm{pH}$ higher than 8 , then they decrease between 8 and 5.5, and level off before a steep increase at pH 4. This complex trend can be interpreted with the help of the results described above. First, the effect of the presence of tungstate on zeta potential below pH 8 is in agreement with the formation of inner-sphere surface complex with $\mathrm{WO}_{4}{ }^{2-}$ assumed from measurements in batch experiments. The plateau seen around $\mathrm{pH} 5.5$ at $20 \mathrm{mV}$ can be explained by different reasons. Thus, it could be due to polymerization of tungstate ions in solution, which decreases the concentration of monomers in solution. These latter species are responsible of the adsorption mechanism at higher $\mathrm{pH}$ (where $\mathrm{WO}_{4}{ }^{2-}$ is the only species), and it can be assumed that the polymers have a lower affinity towards surface, explaining the adsorption end. Another explanation can be the change in the surface speciation, with the protonation of the tungstate surface complexes, in analogy with the protonation of tungstate in solution. In this case, the zeta potential would stop to decrease, even though the adsorbed amount would continue to increase. Of course, both these phenomena could occur together. For higher tungsten concentration, the same trend has been observed, with even lower zeta potential values, in agreement with a larger tungstate adsorption. 


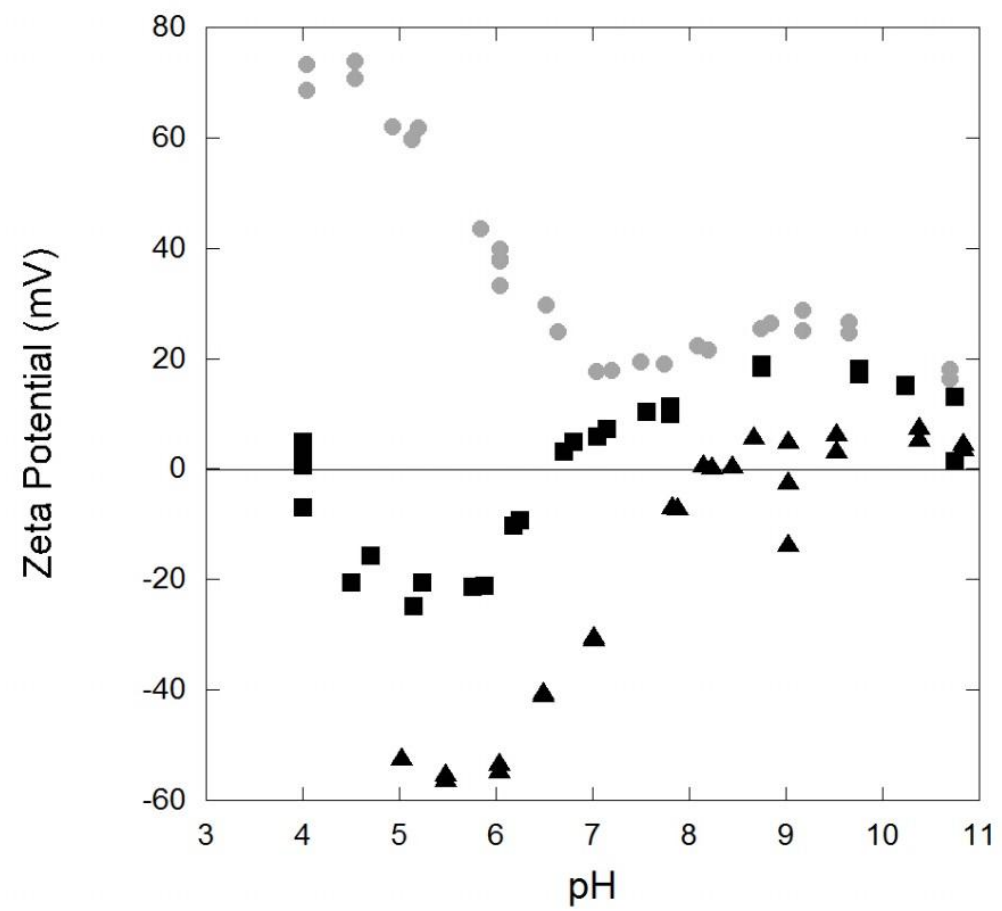

Fig. 4. Zeta potential of hydrotalcite suspensions: LDH only ( $\bullet$ ), with $W 10^{-4} \mathrm{M}(\mathbf{\square})$, with W $10^{-3} \mathrm{M}$ $(\mathbf{A})$.

\subsection{In situ IR spectroscopy}

Since zetametry cannot bring any information on exchanged fraction of the tungstate ions, a complementary method, in situ infrared spectroscopy, has been used. This method has been successfully used previously to show that in a ZnAl layered double hydroxide, the most charged heptamer $\left(\mathrm{W}_{7} \mathrm{O}_{24}{ }^{6-}\right)$ was preferentially exchanged, even when its concentration is lower than those of protonated heptamers ${ }^{12}$. The exchange of tungstate in hydrotalcite has been followed using the same protocols. After depositing a layer of hydrotalcite on the ATR element (see experimental part for more details) and equilibrating it with a flowing electrolyte solution, a background has been recorded. Then, increasing amounts of tungstate has been added in solution (10, 20, $30 \mathrm{mM})$, along with the recording of IR spectra. The raw spectra in absorbance scale are shown in Fig. 5. Due to the background definition, the positive bands correspond to species accumulated in the solid, while negative bands correspond to species released by the solid. This interpretation is complicated by another phenomenon: the evolution of the deposited layer, for example the swelling of the particles 
following the exchange, and/or the release of some particles from the ATR element, would also lead to negative bands. The series of raw spectra can be interpreted from these considerations. Three negative bands are clearly visible, around 1371, 976 and $786 \mathrm{~cm}^{-1}$. The values can be compared with the spectrum of hydrotalcite (Fig. 6A), which is dominated by a band at $1374 \mathrm{~cm}^{-1}$ (assigned to asymmetric stretching of $\mathrm{CO}_{3}{ }^{2-}$ ), and several peaks between 950 and $790 \mathrm{~cm}^{-1}$, assigned to vibration modes of bonds in the hydrotalcite framework. Thus, the negative bands in the series of raw spectra come from a decrease of the signal of the hydrotalcite. However, it can be seen that the intensity of the carbonate band is much higher (in absolute value) than those of hydrotalcite framework bands in the exchange experiment, while it is slightly higher in the hydrotalcite layer. Thus, the negative carbonate band would be the sum of the decreased signal of hydrotalcite and the release of carbonate from the solid, following its exchange by polytungstate ions. This latter phenomenon is supported by the positive peaks located around 951,912 and $836 \mathrm{~cm}^{-1}$, assigned to the vibration modes of $\mathrm{W}_{7} \mathrm{O}_{24}{ }^{6-}$ accumulated in the interlayer of hydrotalcite. To support this interpretation, a decomposition of the spectra has been performed. The first step was to decompose the spectra of the hydrotalcite layer (Fig. 6A) to obtain a fingerprint of the initial solid. This spectrum has been decomposed in five bands: one Voigt band at $1374.3 \mathrm{~cm}-1$ and four Gaussian bands at 1038.8, 946, 868 and $795.8 \mathrm{~cm}^{-1}$. Then, the last spectrum of hydrotalcite obtained during the tungsten sorption step has been decomposed (Fig. 6B). First, only the part corresponding to $1100-700 \mathrm{~cm}^{-1}$ range was considered. The spectrum has been decomposed with a set of 8 Gaussian bands: 4 (negative) corresponding to the hydrotalcite, and 4 (positive) corresponding to the heptatungstate. The spectra of hydrotalcite was constrained by the values obtained with the pure layer (Fig. 6A), with only one free parameter, the intensity of the band at $1038.8 \mathrm{~cm}^{-1}$. For the spectra of heptatungstate, the initial parameters were the number and the location of peaks found previously in a ZnAl LDH ${ }^{12}$. After fitting, it has been possible to show that the experimental spectrum is consistent with the sum of a decrease of the hydrotalcite signal and the increase of the heptatungstate species. The bands found for this latter species were in good agreement with those found in a previous study ${ }^{12}$ despite the fact 
that all parameters for each band (location, width and intensity) were free. Since the decomposition of the spectrum of the hydrotalcite layer has given the quantitative relation between the intensity of the framework bands and those of the carbonate bands, the result of the decomposition can be used to evaluate the fraction of the negative carbonate bands observed in Fig. 5 related to the decrease of the hydrotalcite signal. Thus, this calculation has shown that about $37 \%$ of the negative carbonate bands comes from the decrease of the hydrotalcite signal, while the remaining is due to the exchange of this ion with heptatungstate (Fig. 6C).

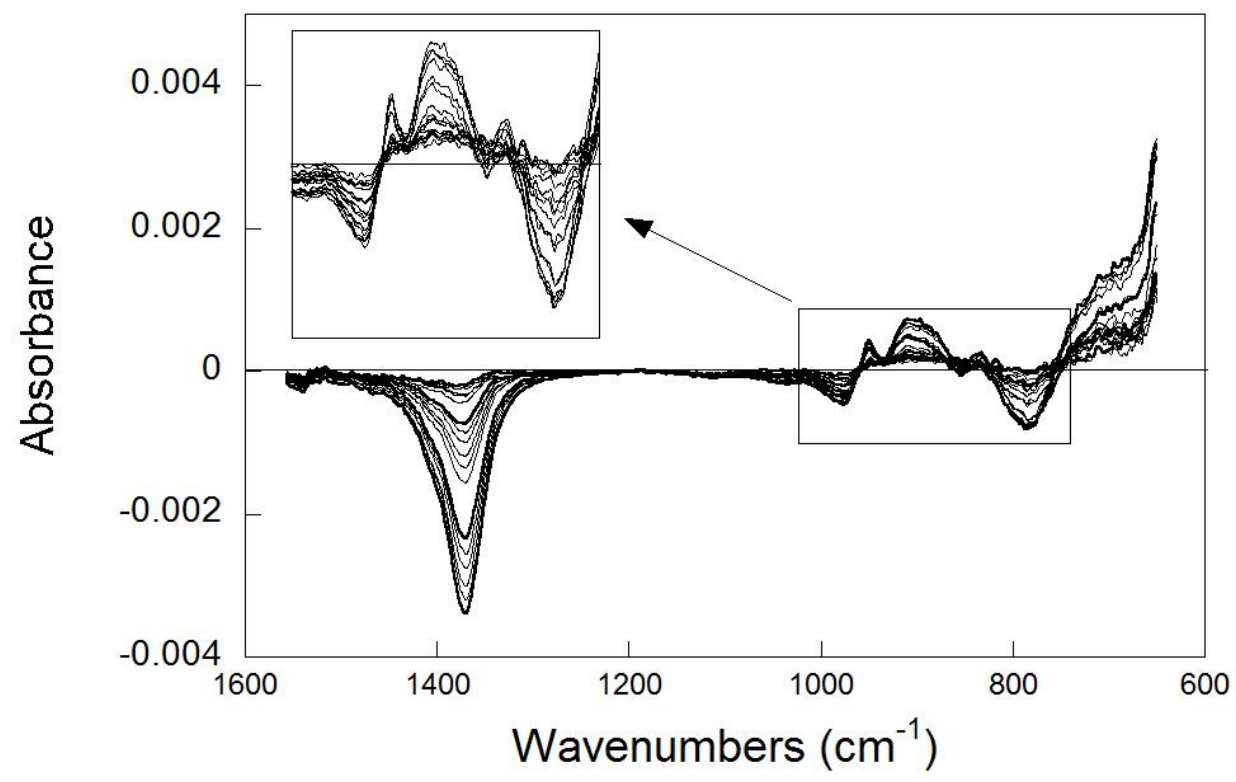

Fig. 5. In situ ATR-IR spectra during tungstate exchange and inset of the tungstate/LDH framework domain. The four thick lines correspond to first spectra in presence of $10^{-4} \mathrm{M}$ (initial time), $2.10^{-4} \mathrm{M}$ (41 min.), and $3.10^{-4} \mathrm{M}$ tungstate (1h35), and last spectra with $3.10^{-4} \mathrm{M}$ tungstate (2h04). Thin lines correspond to spectra regularly recorded between concentration changes. 

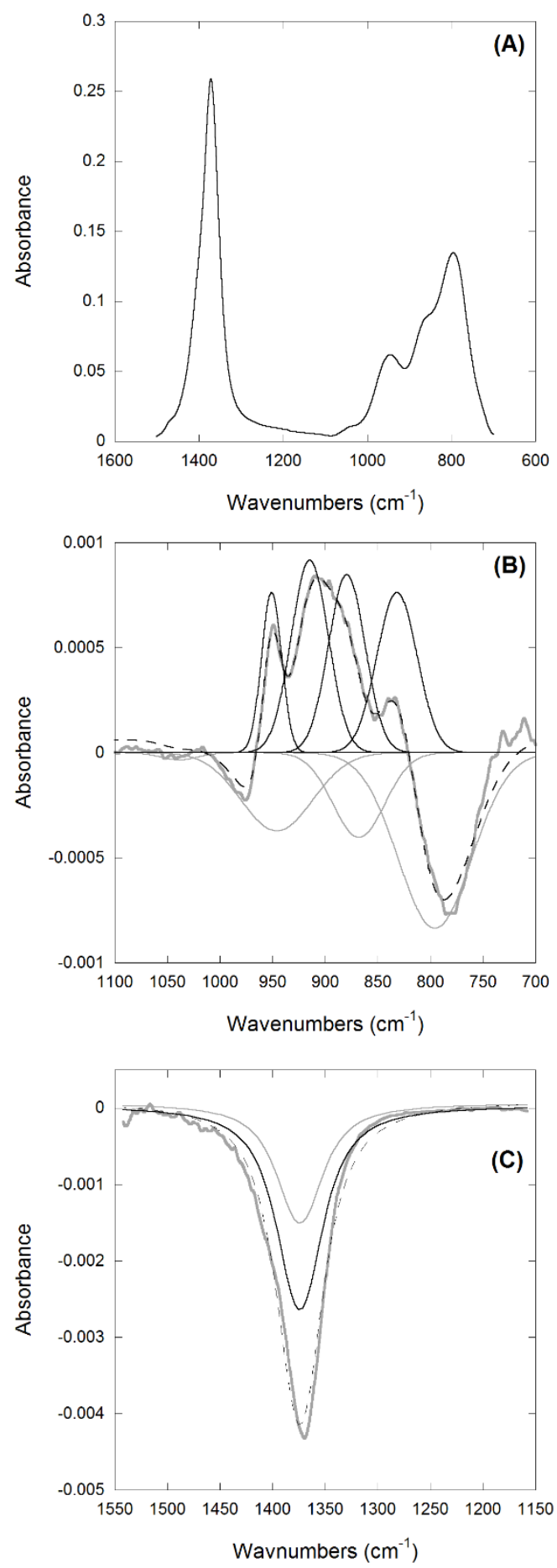

Fig. 6. (A) Spectra of hydrotalcite layer before exchange experiment, (B) decomposition of spectrum at 2h04: experimental spectrum (thick grey line), fitted spectrum (dots), peaks obtained from decomposition for hydrotalcite (thin grey line) and heptatungstate (black line). (C) Decomposition of 
carbonate band at 2h04: experimental spectrum (thick grey line), fitted spectrum (dots), and peaks obtained from decomposition assigned to hydrotalcite signal decrease (thin grey line) and carbonate exchanged by heptatungstate (blak line).

\section{Conclusion}

Hydrotalcite, a LDH with a MgAl hydroxide framework with interlayer carbonate ions, was shown to be able to extract tungsten from aqueous solutions. This solid is the most usual LDH, whose synthesis is easy since it can be made without precautions towards atmospheric carbon dioxide contrary to many others (nitrate-exchanged for example ${ }^{25}$ ). Moreover, a preliminary calcination step is not needed to make it reactive towards the target ions, as often needed with carbonated-LDH ${ }^{26}$. The sorption of tungsten occurs in a large $\mathrm{pH}$ range, from 4 to 8 , and can been explained by different mechanisms. The exchange with carbonate ions takes place when the speciation of tungsten is dominated by polyoxometallate species, and an optimal $\mathrm{pH}$ around 5 has been found in our experiments. The exchanged species $\left(\mathrm{W}_{7} \mathrm{O}_{24}{ }^{6-}\right.$ vs. $\left.\mathrm{CO}_{3}{ }^{2-}\right)$ have been identified by in situ infrared spectroscopy. For higher $\mathrm{pH}$ values, the adsorption of tungstate ions as inner sphere complexes can be assumed, based on zetametric measurements. Accumulated tungsten can be released in an alkaline solution of carbonate sodium, whatever the extraction mechanism, allowing an easy an efficient regeneration of the solid. Moreover, the presence of different anions in solution (chloride, nitrate, sulfate) has no effect on the tungsten uptake, in agreement with the expected selectivity based on the large difference of anionic charge between polyoxometalate and (oxo)anions.

\section{Acknowledgments}

The authors acknowledge financial support from the ParisTech Chair "Urban Mining" sponsored by Eco-systèmes. Maël Borland (IRCP) is acknowledged for the zeta potential measurements. 


\section{References}

(1) Upadhyaya, G. S. Cemented Tungsten Carbides: Production, Properties and Testing; William Andrew, 1998.

(2) Rieck, G. D. Tungsten and Its Compounds; Elsevier, 2013.

(3) Vicente, G.-P. Promoting Sustainable Practices through Energy Engineering and Asset Management; IGI Global, 2015.

(4) Guzman, F. M.; Paz, M. H.; Cohen, L. G.; Rosales, C. J.; Almaraz, V. B. Tungsten and Rhenium Sorption Study on Alumina to Prepare 188W/188Re Generators. Sep. Sci. Technol. 2009, 44 (5), 1120-1143.

(5) Hairunnisha, S.; Sendil, G. K.; Rethinaraj, J. P.; Srinivasan, G. N.; Adaikkalam, P.; Kulandaisamy, S. Studies on the Preparation of Pure Ammonium Para Tungstate from Tungsten Alloy Scrap. Hydrometallurgy 2007, 85 (2-4), 67-71.

(6) Srivastava, R. R.; Mittal, N. K.; Padh, B.; Reddy, B. R. Removal of Tungsten and Other Impurities from Spent HDS Catalyst Leach Liquor by an Adsorption Route. Hydrometallurgy 2012, 127$128,77-83$.

(7) Lende, A. B.; Kulkarni, P. S. Selective Recovery of Tungsten from Printed Circuit Board Recycling Unit Wastewater by Using Emulsion Liquid Membrane Process. J. Water Process Eng. 2015, 8, 75-81.

(8) Paulino, J. F.; Afonso, J. C.; Mantovano, J. L.; Vianna, C. A.; Silva Dias da Cunha, J. W. Recovery of Tungsten by Liquid-liquid Extraction from a Wolframite Concentrate after Fusion with Sodium Hydroxide. Hydrometallurgy 2012, 127-128, 121-124.

(9) Huo, G.; Peng, C.; Song, Q.; Lu, X. Tungsten Removal from Molybdate Solutions Using Ion Exchange. Hydrometallurgy 2014, 147-148, 217-222.

(10) Nguyen, T. H.; Lee, M. S. Separation of Molybdenum(VI) and Tungsten(VI) from Sulfuric Acid Solution by lon Exchange with TEVA Resin. Sep. Sci. Technol. 2015, 50 (13), 2060-2065.

(11) Cao, C.; Zhao, Z.; Chen, X. Selective Precipitation of Tungstate from Molybdate-Containing Solution Using Divalent lons. Hydrometallurgy 2011, 110 (1-4), 115-119.

(12) Davantès, A.; Costa, D.; Lefèvre, G. Infrared Study of (Poly)Tungstate lons in Solution and Sorbed into Layered Double Hydroxides: Vibrational Calculations and In Situ Analysis. J. Phys. Chem. C 2015, 119 (22), 12356-12364.

(13) Prasanna, S. V.; Kamath, P. V. Anion-Exchange Reactions of Layered Double Hydroxides: Interplay between Coulombic and H-Bonding Interactions. Ind. Eng. Chem. Res. 2009, 48 (13), 6315-6320.

(14) del Arco, M.; Carriazo, D.; Gutiérrez, S.; Martín, C.; Rives, V. Synthesis and Characterization of New Mg2Al-Paratungstate Layered Double Hydroxides. Inorg. Chem. 2004, 43 (1), 375-384.

(15) Rives V., U. M. A. Layered Double Hydroxides (LDH) Intercalated with Metal Coordination Compounds and Oxometalates. Coord. Chem Rev 1999, No. 181, 61-120.

(16) Salak, A. N.; Tedim, J.; Kuznetsova, A. I.; Vieira, L. G.; Ribeiro, J. L.; Zheludkevich, M. L.; Ferreira, M. G. S. Thermal Behavior of Layered Double Hydroxide Zn-Al-Pyrovanadate: Composition, Structure Transformations, and Recovering Ability. J. Phys. Chem. C 2013, 117 (8), 4152-4157.

(17) Morimoto, K.; Anraku, S.; Hoshino, J.; Yoneda, T.; Sato, T. Surface Complexation Reactions of Inorganic Anions on Hydrotalcite-like Compounds. J. Colloid Interface Sci. 2012, 384 (1), 99104.

(18) Otgonjargal, E.; Kim, Y.-S.; Park, S.-M.; Baek, K.; Yang, J.-S. Mn-Fe Layered Double Hydroxides for Adsorption of As(III) and As(V). Sep. Sci. Technol. 2012, 47 (14-15), 2192-2198.

(19) Yang, K.; Yan, L.; Yang, Y.; Yu, S.; Shan, R.; Yu, H.; Zhu, B.; Du, B. Adsorptive Removal of Phosphate by Mg-Al and Zn-Al Layered Double Hydroxides: Kinetics, Isotherms and Mechanisms. Sep. Purif. Technol. 2014, 124, 36-42. 
(20) Davantes, A.; Lefevre, G. In Situ Real Time Infrared Spectroscopy of Sorption of (Poly)Molybdate lons into Layered Double Hydroxides. J. Phys. Chem. A 2013, 117 (48), 12922-12929.

(21) Redkin, A. F.; Bondarenko, G. V. Raman Spectra of Tungsten-Bearing Solutions. J. Solut. Chem. 2010, 39 (10), 1549-1561.

(22) Cruywagen, J. J.; van der Merwe, I. F. Tungsten (VI) Equilibria: A Potentiometric and Calorimetric Investigation. J. Chem. Soc. Dalton Trans. 1987, No. 7, 1701-1705.

(23) Davantès, A.; Costa, D.; Sallman, B.; Rakshit, S.; Lefèvre, G. Surface Polymerization of Mo(VI) and W(VI) Anions on Hematite Revealed by in Situ Infrared Spectroscopy and DFT+U Theoretical Study. J. Phys. Chem. C 2017, 121 (1), 324-332.

(24) Kosmulski, M. Chemical Properties of Material Surfaces; CRC Press, 2001.

(25) Kovanda, F.; Maryšková, Z.; Kovář, P. Intercalation of Paracetamol into the Hydrotalcite-like Host. J. Solid State Chem. 2011, 184 (12), 3329-3335.

(26) Koilraj, P.; Srinivasan, K. High Sorptive Removal of Borate from Aqueous Solution Using Calcined ZnAl Layered Double Hydroxides. Ind. Eng. Chem. Res. 2011, 50 (11), 6943-6951. 